\title{
Transformational Leadership Approaches and Their Influence on Teacher Resilience During the COVID-19 Pandemic
}

\author{
Lesley Eblie Trudel \\ University of Winnipeg \\ Laura Sokal \\ University of Winnipeg \\ Jeff Babb \\ University of Winnipeg
}

With stress documented beyond inherent levels in our initial research with Canadian teachers during the COVID-19 pandemic, this case study moves beyond the consideration of individual strategies to reduce burnout, toward an examination of situational approaches to support teachers during this time of disruptive change. Using the Areas of Worklife Model, we present an analysis of in-depth interviews and focus groups with Canadian educational leaders on key transformational leadership approaches that were applied during the COVID-19 pandemic. In addition to observations about contextual factors which led to imbalance and adversity for teachers, insights were gained into leadership approaches which conversely increased balance and engagement resulting in overall enhanced teacher resilience.

Keywords: transformational leadership, teachers, burnout, resilience, change

\section{INTRODUCTION}

In today's school organizations, leadership is seen as the key to positive and effective transformation and change. Kouzes and Posner (2007, xi) contended that leadership is akin to transforming "values into actions, visions into realities, obstacles into innovations, separateness into solidarity, and risks into rewards." Under typical circumstances, educational leaders are central to the development of strategic processes which involve the communication of a strong vision and related outcomes along with a plan for continuous improvement (Smith \& Riley, 2012). Within this paradigm, Keddie and colleagues (2017) maintained that school leaders are accountable to improve student achievement, a performative context that has now been disrupted by the COVID-19 pandemic. Netolicky (2020) added that in a crisis of this nature, school leadership must extend from the usual emphasis on learning to include a focus on well-being, involving the provision of certainty, engagement for effective effort, and assurance of transparent and reliable communication for all members of the educational community.

It is with the crisis of the COVID-19 pandemic in mind that our Canadian research team embarked on a mixed methods research study involving a critical aspect of educator well-being, namely teacher burnout. 
Although not the focus of this case study, for reader context we provide the subsequent description. The research initially focused on three national surveys of 2200 teachers on this topic, as well as qualitative interviews of representatives from the initial survey, followed by an additional phase of the study that involved a mid-Canadian provincial school division of over 800 teachers and the exploration of their educational journey through COVID-19 during the 2020-2021 school year (Babb et al., in press; Eblie Trudel et al., 2021a, 2021b; Sokal et al., 2020a, 2020b, 2020c, 2020d, 2020e). A goal of the additional phase of this research - and the central point of the case study - was to identify leadership practices within the context of the pandemic which would not only help to avoid teacher burnout but could potentially reinforce teacher resilience and well-being. Hence we placed the initial findings of our research within the context of the literature, followed by a discussion of leadership perspectives and approaches as we determined their influence on teacher resilience during the COVID-19 pandemic.

\section{LITERATURE REVIEW}

\section{Teachers and Burnout}

There is extensive international research which recognizes that teaching is both a rewarding but stressful profession (Harmsen et al., 2018; Johnson, 2003; Skaalvik \& Skaalvik, 2015). Well before the pandemic, many teachers reported emotional challenges related to stress experienced in their jobs (Montgomery \& Rupp, 2005). Arvidsson and colleagues (2019) recently noted the types of pressures that seemingly underpinned teachers' perceptions of stress, including: complex work environments; high degrees of face-to-face interaction; time pressures in performance of job tasks; frequent meetings that compromise preparation time; and, requirements of administrative paperwork. Maslach and colleagues (2001) indicated that persistent stress could result in burnout, a condition commonly characterized by emotional exhaustion, cynicism and depersonalization, as well as reduced self-efficacy. They noted that emotional exhaustion often results from excessive demands from an individual's job, whereas loss of efficacy can arise from having insufficient resources to meet those demands. Between the two dimensions of emotional exhaustion and reduced self-efficacy, Maslach and colleagues described cynicism, which is evidenced by individuals pulling back from their roles, and depersonalization, illustrated by individuals pulling away from those with whom they work. In the case of teachers, this could extend beyond challenges to personal resilience, resulting in negative influences on student achievement, behavioural outcomes, and student well-being (Geving, 2007; Wentzel 2010).

Recent research on teacher dissatisfaction has expanded in scope to include the concept of demoralization (Santoro, 2018). Rather than exemplifying more general ethical concerns, demoralization takes the form of teachers being confident in ethical courses of action in their roles, yet realizing that they cannot follow through in an appropriate manner. In effect, they believe that their professional values are persistently compromised, and they experience moral dissatisfaction. Santoro (2018) observed that teachers who are demoralized report similar outward presentations as those experienced during burnout such as exhaustion, frustration, and feelings of ineffectiveness. Demoralization, she added, leads teachers to feelings of guilt and shame, believing that they are undermining their professional responsibilities and ultimately harming their students. It is evident from the research of Santoro that demoralization was present prior to COVID-19, and its effects continued to be felt during the pandemic. While our research team did not initially intend to investigate the concept of demoralization in our studies on burnout, evidence emerged of teachers experiencing chronic conflict in their work environments and the related feelings of frustration or loss of control (Babb et al., in press; Eblie Trudel et al., 2021a, 2021b; Sokal et al., 2020a, 2020b, 2020c, $2020 \mathrm{~d}, 2020 \mathrm{e}$ ). In a recent article (in press), our research team recommended the consideration of demoralization as an additional element together with cynicism and depersonalization, when assessing progression towards burnout.

\section{Causes and Outcomes of Burnout}

Research over the past several decades has demonstrated that increased workload, ambiguity and conflict in roles, as well as stressful events and pressure, may each elicit cognitive, emotional, and physical 
effort (Alarcon, 2011; Demerouti et al., 2001). With sustained exposure to such job demands, individuals become exhausted and distance themselves from their work and colleagues, similar to experiences shared by teachers in our studies during the pandemic (Babb et al., in press; Eblie Trudel et al., 2021a, 2021b; Sokal et al., 2020a, 2020b, 2020c, 2020d, 2020e).

Job resources also play a unique role in the progression toward burnout. Job resources refer to individuals' "physical, psychological, social or organizational aspects of the job that help to achieve work goals and encourage personal growth and development" (Bakker \& Demerouti, 2007, p. 312). While job resources are not as strongly correlated with burnout as are job demands, they demonstrate a consistently negative relationship in terms of cynicism, when individuals are not able to access supports appropriately or use them to mitigate challenging job situations (Demerouti et al, 2001).

More recent research on burnout has included the notion of imbalances leading to role strain. In the Job Demands Resources (JD-R) model, Baker \& Demerouti (2007) noted that it is essential for organizations to maintain balance for employees by establishing outcomes and challenges judiciously, as well as ensuring that adequate resources are available to offset demands so that individuals can achieve their goals. Consistent with JD-R theory, individuals may also access their own personal resources in efforts to counter negative effects of job demands. Recent studies have demonstrated that when personal resources are used by individuals, their well-being and role performance typically improves (Lupsa et al., 2020). We determined through our own studies on teacher burnout during the pandemic that teachers were experiencing the pandemic in different ways (Babb et al., in press; Eblie Trudel et al., 2021a, 2021b; Sokal et al., 2020a, 2020b, 2020c, 2020d, 2020e). Through the statistical process of latent profile analysis (LPA), we found that some of the teachers we surveyed had adequate resources to meet the demands placed on them and remained engaged and involved, while others struggled to cope, feeling overextended, inefficacious, and detached. Remarkably, the noted distinctions correlated with various combinations and levels of job demands, and both internal and external resources. The diversity of responses and patterns of burnout indicated by teachers spoke to the importance of being aware of teachers' levels of resilience when determining the types of resources that might support various individuals to mitigate burnout.

\section{Multi-Dimensional Approaches to Intervention}

Bakker and de Vries (2021) indicated that over time, there has been a shift in the trend toward diagnosing burnout as an individual, psychological construct. They reinforced the idea that key resources or interventions should be considered not only at the personal level, but also at the organizational level. While individual strategies could be adapted from research done on stress and coping, they proposed that initiatives introduced in the workplace such as adjustment of workload demands, changing work patterns, and reduction of overtime work, could contribute to systemic job recovery strategies. Alternatively, Bakker and de Vries suggested that organizations could initiate positive changes to how individuals engaged with their work in a process known as job crafting. Job crafting strategies might include assisting a struggling individual to recognize their fatigue, supporting requests for specific feedback, or arranging a job coaching experience (Pekaar et al., 2018a). In contrast, job crafting at an organizational level might involve restructuring role tasks, as well as, facilitation of mentorship opportunities or professional learning plans (Breevaart et al., 2014). Breevaart and colleagues emphasized the importance of transformational leadership in organizations, and identified behaviours and approaches which served to support, motivate and inspire individuals to achieve daily work engagement.

These types of organizational interventions and the notion of transformational leadership in education were particularly enduring and essential throughout the pandemic, when demands on the education sector were especially difficult. In our research we noted the importance of school principals, who were most familiar with the teachers with whom they worked and had frequent opportunities to observe behavioural changes that could indicate a possible progression towards burnout (Sokal et al., 2020c). Data from interviews with teachers in our study (Eblie Trudel et al., 2021a) indicated that individuals who, with the support of administrators, detached from technology at the end of the school day experienced less stress and coped better during early stages of the pandemic. We also detailed how school and district leaders, through partnerships with human resource departments or external organizations, could transform 
educational environments in challenging contexts through the implementation of proactive programming for teacher resilience and well-being at both individual and organizational levels (Eblie Trudel et al., 2021b).

\section{Evaluating the Efficacy of Leadership Approaches}

Whether teachers were experiencing the demands of their roles without sufficient resources or through a poor match of resources to demands, Santoro (2018) noted that, in general, the imbalance of resources to meet demands and resulting adversity of burnout had traditionally been attributed to a lack of resilience, tolerance, or self-regulation on the part of teachers, rather than to a conflict with practices, policies or other influences in the organizational environment. As a result, the central emphasis to achieve individual resilience had focused on personal strategies to counter burnout (Maslach \& Leiter, 2016) despite the evidence pointing toward greater efficacy in additionally considering situational elements. Through her research on demoralization (which we have argued should be recognized as a component of burnout), Santoro (2018) highlighted the policies and practices external to the individual that affect teacher satisfaction. This socially constructed discourse seemed to offer a more suitable balance between individual and organizational contexts through which to consider the influence of transformational leadership approaches on teacher resilience.

To explore transformational leadership approaches more fully in this case study, we chose to engage the Areas of Worklife (AW) model (Leiter \& Maslach, 1999, 2004; Maslach \& Leiter, 2016) which framed occupational stress in terms of factors in an individual's situational environment. The model is a variation of the previous imbalance scenario associated with JD-R, except this structure extended the types of imbalances to six domains identified as organizational risk factors in many vocations: workload, control, reward, community, fairness and values. Maslach and Leiter (2016) advocated that mismatches in any one of these areas could influence how an individual experiences burnout and, in turn, could affect not only personal well-being but also job performance. They argued that while there was little research evaluating the efficacy of approaches to reduce individual burnout (and increase resilience), there was less study evaluating the effectiveness of organizational leadership approaches to prevent or reduce burnout (thus enhancing resilience). Maslach and Leiter (2016) added that it was unclear as to whether burnout could be mitigated directly by specific resources and strategies for individuals, or whether it was more effective to match specific strategies within the context of the organization. Our research team provided additional clarity regarding individual supports and resources to reduce burnout, in our analysis of Canadian teachers responding to the demands of the pandemic (Babb et al., in press; Eblie Trudel et al., 2021a, 2021b; Sokal et al., 2020a, 2020b, 2020c, 2020d, 2020e). In this case study we will respond more specifically to organizational approaches, as a result of our qualitative inquiry with educational leaders.

\section{METHODS}

\section{Design}

A case study approach was chosen for this stage of the research, to convey an in-depth understanding of the perspectives of educational leaders in a provincial school division. As a response to COVID-19 health restrictions and with a mind to capture data in situ during the second and third waves of the pandemic, we engaged in qualitative interviews and focus groups completed remotely on Zoom. This was the second phase of a larger study that was approved by the Human Ethics Research Board of the research team's university. The entire study met the standard of the TCPS-2 (certificate \#14993) and was funded by a Partnership Engage Grant through the Social Sciences and Humanities Research Council of Canada.

\section{Participants}

The data collection for this case study featured voluntary participation in qualitative interviews which occurred in winter 2021, with a purposive sampling of representatives of the superintendent's team (division administrators), board of trustees (school trustees) and principals or vice-principals (school leaders). An email was sent via the school division to solicit interest in this interview process. If educational leaders 
wished to participate they could submit a consent form for further involvement. The inquiry process included three, one-hour interviews and a one-hour focus group. Two division administrators were interviewed individually, two school trustees were interviewed together, and five representatives of school leaders were interviewed as part of the focus group.

\section{Measures}

Given the diverse nature of the work involving different members of the educational leadership team, the discussion guides for qualitative interviews were targeted to focus on the nature of each role. For example, the conversation with division administrators involved queries into organizational leadership before and during the pandemic, provision of equitable resources, facilitation of professional learning opportunities for staff, necessary partnerships to bridge new opportunities, support of staff to manage workloads and ensure social-emotional well-being, as well as, information on organizational challenges and opportunities. With the school trustees, we discussed differences in board leadership approaches since COVID-19, shifts in areas of focus for the board of trustees, strategies for communication, accountability for learning, community partnerships, as well as challenges and opportunities in school district governance. In the dialogue with the school leaders focus group (principals and vice-principals), the conversation centered on shifts in administrative priorities given the pandemic, equitable learning opportunities for students, support of professional learning for teachers, school partnerships, support for the well-being of school administration, staff and students, in addition to challenges and opportunities in the school environment.

\section{Data Analysis}

From an ontological standpoint, the data from the interviews and focus group were initially viewed through a relativist, interpretive paradigm (Greener, 2008). The transcript data was disaggregated through the process of abductive analysis (Järvensivu \& Törnroos, 2010) whereby ideas were systematically combined through a technique of elaborative coding, according to the empirical framework of the AW model (Leiter \& Maslach, 1999, 2004; Maslach \& Leiter, 2016). The AW model, described earlier, allowed us to explore balances, imbalances, matches and mismatches, as a result of six organizational risk factors discussed by educational leaders: workload, control, reward, community, fairness, and values. The subsequent analysis in this case study consists of a detailed exploration of empirical data collected during the second and third waves of the COVID-19 pandemic.

\section{FINDINGS}

The interview and focus group data from educational leaders in the provincial school division were reviewed with the following essential question in mind: How did transformational leadership approaches applied during the COVID-19 pandemic influence teacher resilience? Through the AW model (Leiter \& Maslach, 1999, 2004; Maslach \& Leiter, 2016) we observed that the greater the imbalance or mismatch, the increased likelihood of burnout, while the greater a balance or match, the more likely an individual would remain engaged and resilient in their work. The six areas of worklife are defined first along with related insights from educational leaders on identified areas of mismatch which they believed had contributed to imbalance. This is followed by approaches they took to achieve greater balance or match for individuals in the school division during the pandemic.

\section{Areas of Worklife \\ Overload}

Maslach and Leiter (2016) described work overload contributing to burnout, as the result of a depletion of the capacity of individuals to do their jobs. They suggested that administrators could alleviate this mismatch by ensuring that workloads were manageable and sustainable, with opportunities for learning and skill refinement. When asked about supporting teachers to manage workload demands, division administrators conveyed the sense that during the pandemic, energy was a precious commodity. "Initially, 
when teachers shifted to remote learning, things really ramped up. We (the division) would do webinars all day long, with different teachers doing presentations - and they would all fully subscribe. People were hungry for how they could adapt to this new challenge, do it reasonably well and feel good about what they were doing. At a certain point, I think we sensed that people started to tire." Whereas prior to the pandemic, school leaders worked with teachers on creative solutions and opportunities, this goal was now identified as more of a challenge. "We wanted to help teachers use their imagination to see through a problem, but then their imaginations were clouded by what seemed like an impossibility. They didn't have the energy necessarily to be as creative as they wanted to be." Nonetheless, division administrators added the notion of being careful not to pressure too much. "The biggest thing around workload was telling people, 'It's okay, take a deep breath. You're not going to be as effective as you normally are, but just do your best'. And anecdotally when you say that to a teacher, you can see the load being taken off, just through their eyes. It was the first time they were told they didn't have to do everything; Less is more - the golden rule of the pandemic." The reduction of demands was intuitive, as there was a sense by division administrators that teachers might be trying to replicate what they typically did in the classroom by trying to be online for almost six hours a day. By shifting expectations, providing resources such as additional teacher staffing to reduce class sizes, and ensuring the continuation of teacher collaboration, the division noticed an increase in engagement and fewer teachers accessing sick time. A school leader added, "teachers put a lot of pressure on themselves, regardless where they are and what's happening. They have this responsibility to students, and they are wanting to do the very best. But they need to be well also, because if they're not, it's not going to be good for students." School trustees likewise elaborated on the school board's contributions to keep workloads manageable. "We made sure to keep class sizes down. Whether it was COVID or not, we supported teachers to support learners." This was not an easy task according to school trustees. With cuts from the government, the school board was forced to eliminate one of the division administration positions and reduce programs, resulting in less leadership and resources for schools, teachers and students. "It's been really tough to keep programs going. And because they (the government) took a long time to tell us what the budget was, it was hard to plan." The government also deferred the role of contact tracing to school leaders which added to what they described as plates that were already full. One school leader contended, "it became an ethical responsibility. If you heard information and it impacted on your school community, you needed to act. So, whether it was phoning over and over again or making decisions that you felt should not be yours, decisions needed to be made in that moment." Where public health was overwhelmed, you just did the very best you could, hoping you made the right decision and learned from it as you moved forward." Another school leader concluded by saying, "I think by reducing everybody's anxiety, giving them as much as I could, kept everyone feeling like they could keep going." With additional responsibilities in the areas of health and safety however, school leaders felt overwhelmed and were less available to support the increased demands of the pandemic that teachers were experiencing.

\section{Control}

Control or lack thereof involved the regulation of factors that were direct links to burnout. Maslach and Leiter (2016) indicated that perception of capacity to affect decisions that impact work, the ability to achieve professional autonomy, and the possibility to access resources to complete a job could all contribute to job engagement. In that light, administrators in the school division spoke of the necessity to ensure that staff remained calm and solution focused during a time of upheaval and uncertainty. Division administrators approached situations as they arose, ensuring that staff concerns were minimized. For example, after a period of remote home-based instruction in the spring of 2020 when teachers were asked to return to classrooms to meet with students in small groups, educational leaders and the division's human resources department stepped up to assist approximately eighty teachers in locating daycare spaces for their young children. The division felt it was necessary for teachers to be back with their students and endeavoured to support them effectively to do so. One school leader elaborated on the process. "Our school has a partnership with a separate daycare organization that's housed within our building. We asked the division if they could please check to see whether the daycare organizations were willing to take care of teachers' children. We partnered with the daycare, and they were gracious enough to say 'absolutely, we can'. You 
know, teachers were given very little time to figure out childcare arrangements, and we explained that noone was going to drop off their child with a stranger in the middle of a pandemic, so they could start teaching again." Division administrators shared that upon return to the classroom in June 2020, some teachers felt that they were actually thriving despite the pandemic. As a result, division administrators expressed the need to listen, and understand how to best provide resources and support for teachers who were engaged and involved. Professional development was one way to craft engagement. School leaders found, however, that - for good reasons - there was not the emphasis on professional learning with typical pedagogical topics. "We had ideas in our school plan, and our PD days were based on what our school plan said. When it came to the pandemic, that all went out the window, and we needed to focus on understanding how to do remote learning. There was consideration for mental health and well-being, because we recognized that was a component of remote learning, but the more content-based pieces were pushed aside." In addition, much of the support to schools that followed involved safety training. Division administrators indicated that support for school leaders appeared to be on a continuum, with some preferring to have the freedom to interpret directives from government or from the division itself, while others would say "the division needs to manage this more." Divisional administrators found it helpful to know school leaders well and understand individual needs. "I think there is a spectrum. Before the pandemic some school leaders called me every day, whereas others were happy that I dropped by once a week." Division administrators followed up with the idea that, at times, school leaders appreciated receiving divisional direction as that would support the work and direction schools were trying to achieve. "Sometimes they just needed someone with a bird's eye view to be able to say it's okay." School trustees noted that prior to the pandemic they felt confident in decisions made at the board table, as board members had opportunities to visit schools. During the pandemic, however, that was no longer possible. "Some of what we found very valuable was going to school events, just talking to people. Parents haven't been in the schools either. So, it's kind of a strange thing to have this whole information and observation path cut out." Trustees reinforced that much of the planning of the school board suddenly shifted in focus, "making sure students were two meters apart, that there was personal protective equipment (PPE), that there were enough shields." One trustee provided a reminder that the provincial government had sent masks to the division that were out of date. "Immediately a courier was sent around to pick all of that up, and a second courier delivered new material. So there was no mix up, it was taken away, and the problem was dealt with immediately, whereas we could see that other places were still trying to sort it." It was critical to respond in this manner, as the mask debacle contributed to teachers feeling undermined and devalued by the government. If not dealt with promptly by educational leaders, this situation could have resulted in further dissatisfaction and demoralization noted by Santoro (2018). School trustees summarized that during the pandemic, much of their board meetings were dominated by safety dialogue rather by the usual educational programming discussions. "I think as a board, we've tried to keep that in mind and not add in pressure. We've just followed what public health has said, so the information has been consistent. I think that's been our success, because we have not added other layers to it."

\section{Reward}

The idea of reward was espoused by Maslach and Leiter (2016) as indicative of responses that could ultimately strengthen or weaken behaviours. They asserted that when social, financial, or institutional recognition was absent or insufficient, it might increase individuals' vulnerabilities, whereas when rewards were appropriate and consistent, they increased workplace satisfaction. In that regard, one of the division administrators spoke of the importance of acknowledging the work of teachers, especially during the pandemic. "Much of our work at schools involved being visible. Every meeting that I am having with teachers and principals, it's just thanking them for being in the trenches, appreciating their work, honouring what they are doing, and taking the time to identify when teachers are actually thriving." Another division administrator recounted important gestures of appreciation that were arranged to thank teachers for their additional contributions during the pandemic. "After school one evening, everyone did a drive through. They got a box of chocolates from their administrators' association and picked up a meal that had been arranged at a local restaurant. I think we needed to be celebratory with some of the stuff that teachers were 
doing." The school trustees related a similar gesture, providing a lunch during an additional professional development day. "We as a board agreed to provide a lunch for all the staff just to make sure that they knew we were thinking about them, that we appreciated what they were doing." Division administrators emphasized the immediate reinforcement and support of powerful instruction through the provision of opportunities for teachers to engage with experts and with each other. "The professional learning now, I would say, has been more 'just in time' as opposed to over the next five years. Teachers were telling us this is what they need - so let's get it to them." The school trustees elaborated, "We let teachers be teachers. If they came up with a great idea and they told us about it, or they told their administrator about it and it benefited students in any way shape or form, we tried to find the money to support them." For teachers who were engaged and thriving, division administrators told us about access to the school division's PD fund. In the past it had been used to support attendance at professional learning conferences, however during the pandemic, teachers were approved to use the funds to support graduate course work. "Our post-secondary draw out of that account has probably quadrupled. People have gone back into graduate work, because they are thirsty for it. We have started a university cohort on inquiry with thirty teachers. People were wanting to do something other than think about COVID for a bit!"

\section{Community}

The idea of community signaled the relationships that teachers had with educational leaders to support their daily work with students, families and communities. Maslach and Leiter (2016) held that relationships that lacked trust and support or had residual conflict were said to be at risk of burnout. Conversely, when collegial relationships were effective and social support systems existed in the workplace, individuals were more apt to experience engagement with their respective roles. In this regard, one school leader described the challenges of supporting their school community during the pandemic. "I was trying to pull everybody to winter break, and if they could just get there, then everyone could deescalate. I think it is a part of leadership, hoping that you can help your staff students and families to navigate (through challenges). There's a lot of responsibility, and it does take a lot of energy. It is being that middle person, hopefully providing the best information that I could." Division administrators described that despite the challenges of the pandemic in the 2020-21 school year, ninety per cent of students were supported in community schools. For students who were immuno-compromised, the division arranged for their instruction through the division's own remote learning center. This approach upheld the philosophical underpinnings and inclusive approaches of supporting students as much as possible within local catchment area schools. Trustees added that during periods of remote learning, educational assistants were redeployed, which was not the case in all school divisions. "Our educational assistants were extremely important, going out and visiting homes at a distance, delivering supplies and reading with children." Division administrators noted that throughout the year, classroom teachers were consistently checking on their students who were not in class. "We encouraged staff to watch out for the well-being of families overall." One school leader recalled that videos were sent home by a school, with all the teachers saying hello and telling them how much they missed their students. Another school leader recounted a car parade arranged by teaching staff to re-connect with students during periods of remote learning. "It was very emotional because we had been away from our students for so long and then to see them waving with signs in the community, it was a really humbling experience." A division administrator added, "In our school division, we have tremendous connections between our schools and our families. We know most of our parents by first name." Communication and collaboration were seen as essential elements for the success of the community. "I think for us, as an educational leadership team in the division, coming together frequently and often and working as a team (was important)." A school leader reiterated the importance of meeting regularly as a school staff. "Things were shifting so quickly, we were having frequent meetings every few days and what was valid and accurate one week had changed by the time we got into the next." Division administrators did indicate that they were operating with fewer board meetings than before the pandemic, hence trust and knowledge of core values were key. As one administrator put it, "I would say when navigating (with the board), you're resting on what you've developed already. As a division we have a strong culture and set of core beliefs." School trustees expressed dissonance with those beliefs when describing communication from the government. 
"The government has not been forthcoming, and it's really been very difficult to plan (for the school division) as a board." They noted that the government had been foreshadowing amalgamation with other school divisions in a provincial education review, which was contrary to the values, beliefs and directions indicated by school leaders, teachers, and community members. Ongoing suggestions of education reform, coupled with the demands of the teaching during the pandemic, resulted in a chronic lack of certainty and predictability in work environments.

\section{Fairness}

Fairness is a concept that arose from research on social justice and equity. Maslach and Leiter (2016) elaborated that fairness involved the perception that work decisions were being made justly and equitably. Both the quality of the process and personal experiences would allow individuals to determine whether they were being treated fairly in the community. Maslach and Leiter warned that anger and cynicism could result when individuals believed they were not afforded respect. All educational leaders spoke of strong commitments to equity and social justice in the school division. One of the division administrators indicated a need to be declarative about decisions made early on. "We resolved that we were going to put out as many devices as we needed for remote learning in that early phase (of the pandemic)." Division administrators spoke passionately about the challenges of equity in the school division community. They indicated that the real instructional challenges for teachers were dependent on families and students having resources to support both academic and social emotional learning. "When we were rolling out devices, our media staff visited one of our families. You had two parents and three kids all working around the same kitchen table, remote learning and doing their jobs. And then there was another video clip I saw of a student who was doing a dance piece and sending it to his teacher. He had his laptop open, the camera on recording him, his phone open, and he was in his own room. You know those differences are gradient, and it was really hard to bridge them." A school leader spoke further about the equity issues surrounding technology. "If you're working on a phone outside of a Starbucks because that's where you can get wi-fi and the Starbucks isn't open, it's more difficult to do your work than when you've got the iPad and the computer like some [students] do." For that reason, educational leaders also spoke about the importance of ensuring that as many students as possible were able to connect to technology during periods of remote learning, at summer programming, and when they went back to school in fall 2020. "That's why we had 2500 students in summer programs, because we not only had to get kids back in school, we had to get them out of the house, doing physical activity, playing their instruments. This was great in the summer when we could do that, but I think the way our society is structured, there are still going to be those obstacles for twenty per cent of students living in poverty and for kids in care. COVID has exacerbated that, but we tried to maintain at all cost, the home visits, the phone calls, maintaining learn to skate, learn to swim, after school programs and all the things of value." Division leaders added the importance of equitable and regular access for teachers to engage with each other and with experts in the field. Efforts of this nature continued to enhance the culture of practice, reflection and learning throughout division schools in ways that would benefit not only the teachers, but the students as well. "So, there's been an incentive. We're going to talk about technology, pedagogy and whatever your jam is, we're going to bring you into that."

\section{Values}

Values are characterized as the motivations and visions that initially attract people to engage in their jobs. Maslach and Leiter (2016) inferred that values move beyond wages or advancement in exchange for investment of time and talent. They identified that when values are in conflict due to a gap between individual beliefs and organizational practices, this can result in employee burnout. One of the division administrators shared examples of charitable spirit that had increased on the part of staff during the pandemic. "Our donations this year were just off the charts, school by school. For us, the strong, evident core values were present, and that was the most impactful thing." When school trustees spoke about Educational Assistants delivering hampers to families, they reinforced the adage, "If you're hungry, you can't learn!" One trustee added, "Hopefully people who hear about that will realize that if we are giving food hampers now, we must have been providing food when students were going to school regularly. I 
don't think people understand how much schools feed children." The division was conscious of mental health and well-being, finding that resource availability changed during the pandemic. One school leader added, "critical situations have always been there, but resources haven't. They are now there in an accessible way, so that's been a shift for us." Division leaders felt not only a strong value of care, but also of excellence. "We had to make sure we were taking care of each other, but we had to make sure that we were designing powerful experiences for learners that needed us the most - those living in poverty, those living with trauma, those who were traditionally racialized and excluded, even though we had the best intentions in the system." In that vein, the school division invested funds to be able to create those powerful learning experiences. "We've thrown a ton of resources at schools." One of the school leaders concurred, "it was a remarkable kind of foresight from leaders in our division and a recognition of what was really important at the time - there was this understanding that academics could support mental health." School trustees shared that the board was intentional about students learning remotely during this time. "It was not just about providing a device. Some students did not have internet service at home. So, we ensured that were no roadblocks." Division administrators also spoke to the changes that many school divisions experienced as a result of the COVID-19 pandemic and how values factored into decision making. "For us and particularly early on, divisions were laying off significant numbers of people. We really worked hard to see that all of our employee groups were part of the conversation and felt included and valued. We did not lay people off and that as a result has earned a lot of good will that has helped us."

\section{DISCUSSION}

Through the process of qualitative inquiry, it was revealed that educational leaders in this provincial school division not only provided contextual observations of the work environment during the pandemic that contributed to stress and imbalance, but also provided rare insights into transformational leadership approaches (Breevaart \& Bakker, 2018) that enhanced balance and engagement for teachers. The observations and insights were consolidated within each aspect of the AW model (Maslach \& Leiter, 2016).

In terms of managing work overload for teachers, educational leaders focused on regulating job demands (Baker \& Demerouti, 2007) and keeping school environments as calm, consistent and predictable as possible. It was noted, however, that provincial government budget cuts made for challenges in terms of sustainability of positions and programs which created additional uncertainty in the educational environment. Furthermore, the task of public health contact tracing which was deferred by the government to school divisions, took valuable time and energy away from school leaders who were depleted of their capacity to appropriately address their primary responsibilities to teachers, students and community during the pandemic.

To enhance control, educational leaders worked to regulate factors which could have otherwise reduced professional autonomy, while assisting teachers to gain access to resources which allowed them to remain in their classrooms. The contributions through organizational regulation allowed for specific resource provisions, depending on individual circumstances and needs. The key finding here involved a confirmation of the varied ways that the pandemic had been experienced and a recognition of the diversity of organizational supports which could be provided in response (Babb et al., in press).

One of those supports included the acknowledgement and recognition of the work of teachers during this uncertain time. The school division not only detailed gestures of appreciation but also offered occasions for professional learning and development. This was especially salient during the pandemic, given the challenges of burnout and related impact on individual energy, role satisfaction, and related feelings of reduced efficacy in job performance. Rewards established by the school division could be viewed as organizational job crafting opportunities, facilitated to reinforce, support and engage teachers (Breevaart et al., 2014).

The concept of community was held firmly by all distributions of leadership in the school division. From supporting students in community schools to adapting education as part of the division's remote learning center, educational leaders forged communication, collaboration and connection with staff, students and families. Accordingly, the positive existing relationships within the school division were 
sustained and nurtured. In contrast, school trustees expressed frustration that a similar result was not experienced in terms of the relationship of the school division with the provincial government. The contentious issue of education reform that was continuing to be advanced by the government during the pandemic was in direct conflict with school division and community values, creating a scenario of mismatch, dissatisfaction and loss of control, typically associated with feelings of demoralization outlined by Santoro (2018).

The element of fairness was centered on a strong commitment that this provincial school division declared early in the pandemic. Educational leaders worked diligently to ensure access to technology and programs that were valued by the community. With the provision of resources to families in poverty and for students in care, division administrators observed that instructional challenges for teachers could be substantially reduced, as equity of opportunity for students increased. This sense of equity was extended to teaching staff through the provision of resources for new pedagogies which emerged through and were demanded by the pandemic for related professional learning.

Educational leaders spoke of the omnipresent core values which were universal in this school division. Key practices such as nutrition and resource distribution solidified the context of support for families living in poverty and experiencing food insecurity. The provision of powerful in-person and online learning experiences bridged the challenges of academic continuity and social emotional well-being, which were continuous through the waves of COVID-19.

\section{IMPLICATIONS}

Were the transformational leadership approaches applied in this school division effective in influencing teacher resilience? The voices of educational leaders indicated that transformational leadership approaches not only helped to foster engagement such that individuals could meet the challenges of day-to-day tasks, but also sustained involvement when individuals were confronted by excessive demands that presented themselves during the pandemic. By analyzing the data in this case study through the lens of the AW Model (Maslach \& Leiter, 2016), it became clear that transformational approaches of educational leaders in this provincial school division set the organizational tone and context for individual resilience in terms of balance, adaptation and recovery. That said, educational leaders identified that the actions of the provincial government created mismatches or imbalances with the work that was being done, which negatively influenced the work of teachers the school division. While educational leaders in this organization were successfully invoking changes over time with the intention of producing positive outcomes for teachers, the interplay of political forces persisted in destabilizing the system at both individual and organizational levels. Resilience, nonetheless, has been defined as "the capacity of a dynamic system to adapt successfully to disturbances that threaten systemic function, viability or development" (Masten, 2014, p. 6). Further, Ungar (2021) suggested that regardless of how we define a system, resilience requires us to think of the interactions between people and their environments. In the case of this provincial school division, teacher work overload was regulated and managed, provisions were made to ensure professional autonomy, recognition was provided to acknowledge difficult work circumstances, collaboration and connection were established to enhance the concept of community, and core values of care, excellence and equity were embraced. Through deliberate transformational approaches of educational leaders, organizational and individual values were aligned, reducing the likelihood of teachers experiencing traditional components of burnout and elements of demoralization, thereby enhancing the possibility of greater teacher resilience.

\section{LIMITATIONS AND CONCLUSIONS}

Despite qualitative methods allowing for rich and in-depth understandings, issues of reliability, validity, and generalizability are often called into question in research of this nature. It can also be difficult to reach conclusions and generalize results, due to small sample sizes. Additionally while triangulation of data between division administrators, trustees and school leaders provides greater confidence that the six areas of worklife have been addressed, it is possible that teachers did not experience these actions in a similar 
way. Nonetheless, we believe that the qualitative case study approach selected to present this research, offered insights which would allow readers to reconstruct knowledge in a manner that is personally applicable to their context. We also trust that much can be learned vicariously through the detailed, narrative accounts of educational leaders, according to the multi-factorial analysis of the AW model.

\section{ACKNOWLEDGEMENT}

We would like to recognize the gracious support of the Social Sciences and Humanities Research Council of Canada (SSHRC) in the form of Partnership Engage Grant \#1008-2020-0015.

\section{REFERENCES}

Alarcon, G. (2011). A meta-analysis of burnout with job demands, resources, and attitudes. Journal of Vocational Behavior, 79(2), 549-562. doi: 10.1016/j.jvb.2011.03.007

Arvidsson, I., Ulf, L., Larsson, A., Håkansson, C., \& Persson, R. (2019). Burnout among school teachers: Quantitative and qualitative results from a follow-up study in southern Sweden. BMC Public Health, 19(1).

Babb, J., Sokal, L., \& Eblie Trudel, L. (in press). THIS IS US: Latent profile analysis of Canadian teachers'resilience and burnout during the COVID-19 pandemic. Canadian Journal of Education.

Bakker, A., \& Demerouti, E. (2007). The job demands-resources model: State of the art. Journal of Managerial Psychology, 22, 309-328. doi: 10.1108/01425450710826122

Bakker, A., \& de Vries, D. (2021). Job Demands-Resources theory and self-regulation: New explanations and remedies for job burnout. Anxiety, Stress, \& Coping, 34(1), 1-21. doi:10.1080/10615806.2020.1797695

Breevaart, K., \& Bakker, A. (2018). Daily job demands and employee work engagement: The role of daily transformational leadership behaviour. Journal of Occupational Health Psychology, 23(3), 338-349. doi: 10.1037/ocp0000082

Breevaart, K., Bakker, A., Hetland, J., Demerouti, E., Olsen, O., \& Espevik, R. (2014). Daily transactional and transformational leadership and daily employee engagement. Journal of Occupational and Organizational Psychology, 87(1), 138-157. doi: 10.1111/joop.12041

Demerouti, E., Bakker, A., Nachreiner, F., \& Schaufeli, W. (2001). The job demands-resources model of burnout. Journal of Applied Psychology, 86(3), 499-512. doi: 10.1037/0021-9010.86.3.499

Eblie Trudel, L., Sokal, L., \& Babb, J. (2021a). Teachers' voices: Pandemic lessons for the future of education. Journal of Teaching \& Learning, 15(1), 4-19. doi: 10.22329/jtl.v15i1.6486

Eblie Trudel, L., Sokal, L., \& Babb, J. (2021). Planning for teacher recovery from the COVID-19 pandemic: Adaptive regulation to promote resilience. Interdisciplinary Education and Psychology, 3(1), 1.

Geving, A. (2007). Identifying the types of student and teacher behaviours associated with teacher stress. Teaching and Teacher Education, 23, 624-640.

Greener, S. (2008). Business Research Methods. Ventus Publishing.

Harmsen, R., Helms-Lorenz, M., Maulana, R., \& van Veen, K. (2018). The relationship between beginning teachers' stress causes, stress responses, teaching behaviour and attrition. Teachers and Teaching, 24(6), 626-643. doi: 10.1080/13540602.2018.1465404

Järvensivu, T., \& Törnroos, J. (2010). Case study research with moderate constructionism: Conceptualization and practical illustration. Industrial Marketing Management, 39(1), 100-108. doi: 10.1016/j.indmarman.2008.05.005

Johnson, B. (2003). Teacher collaboration: good for some, not so good for others. Educational Studies, 29, 337-350.

Keddie, A., Gobby, B., \& Wilkins, C. (2017). School Leadership and Management, 38(8), 1-17.

Kouzes, J., \& Posner, B. (2007, xi). The leadership challenge (4th ed.). Wiley. 
Leiter, M., \& Maslach, C. (1999, spring). Six areas of worklife: A model of the organizational context of burnout. Journal of Health and Human Services Administrators, pp. 472-489.

Leiter, M., \& Maslach, C. (2004). Areas of worklife: A structured approach to organizational predictors of job burnout. In P. Perrewé \& D.C. Ganster, (Eds.), Research in occupational stress and well being: Emotional and physiological processes and positive intervention strategies (pp. 91-134). Oxford, UK: JAI Press/Elsevier.

Lupsa, D., \& Virga, D. (2020). Psychological capital, health and performance: The mediating role of burnout. Psihologia Resurselor Umane, 18(1), 7-22. doi: 10.24837/pru.v18i1.458

Maslach, C., \& Leiter, M. (2016). Understanding the burnout experience: Recent research and its implications for psychiatry. World Psychiatry, 15(2), 103-111.

Maslach, C., Schaufeli, W., \& Leiter, M. (2001). Job burnout. Annual Review of Psychology, 52, 397422.

Masten, A. (2014). Global perspectives on resilience in children and youth. Child Development, 85(1), 620. doi: $10.1111 /$ cdev.12205

Montgomery, C., \& Rupp, A. (2005). A meta-analysis for exploring the diverse causes and effects of stress in teachers. Canadian Journal of Education, 28(3), 458-486.

Netolicky, D. (2020). School leadership during a pandemic: Navigating tensions. Journal of Professional Capital and Community. doi: 10.1108/JPCC-05-2020-0017

Pekaar, K., Bakker, A., Van Der Linden, D., \& Born, M. (2018a). Managing own and others' emotions: A weekly diary study on the enactment of emotional intelligence. Journal of Vocational Behavior, 109, 137-151. doi: 10.1016/j.jvb.2018.10.004

Santoro, D. (2018). Is it burnout? Or demoralization? Educational Leadership, 75, 10-15.

Smith, L., \& Riley, D. (2012). School leadership in times of crisis. School Leadership and Management, $32(1), 57-71$.

Skaalvik, E., \& Skaalvik, S. (2015). Job satisfaction, stress and coping strategies in the teaching profession - What do teachers say? International Education Studies, 8, 181-192. https://doi.org/10.5539/ies.v8n3p181

Sokal, L., Eblie Trudel, L., \& Babb, J. (2020a). Supporting teachers in times of change: The job demands resources model and teacher burnout during the CoVID-19 pandemic. International Journal of Contemporary Education, 3(2). doi: 10.11114/ijce.v3i2

Sokal, L., Eblie Trudel, L., \& Babb, J. (2020b). Canadian teachers' attitudes toward change and technology, efficacy, and burnout during the initial wave of the COVID-19 pandemic. International Journal of Educational Research-Open. doi: 10.1016/j.ijedro.2020.100016

Sokal, L., Eblie Trudel, L., \& Babb, J. (2020c). I've had it! Factors associated with burnout and low organizational commitment in Canadian teachers during the second wave of the COVID-19 Pandemic. International Journal of Educational Research-Open. doi:10.1016/j.ijedro.2020.100023

Sokal, L., Eblie Trudel, L., \& Babb, J. (2020d). Opportunity solving: Ordinary people doing extraordinary things, every day. Education Canada. Retrieved from https://www.edcan.ca/articles/opportunitysolving/

Sokal, L., Eblie Trudel., \& Babb, J. (2020e). It's okay to be okay too. Why calling out teachers' 'toxic positivity" may backfire. Education Canada, 60(3). Retrieved from https://www.edcan.ca/articles/its-ok-to-be-ok-too/

Ungar, M. (Ed.). (2021). Multisystemic resilience: Adaptation and transformation in contexts of change. Oxford University Press. Retrieved from https://resilienceresearch.org/wpcontent/uploads/2021/02/Multisystemic-Resilience.pdf

Wentzel, K. (2010). Students' relationships with teachers. In J.L. Meece \& J.S. Eccles (Eds.), Handbook of research on schools, schooling, and human development (pp. 75-91). Routledge. 